\title{
Randomised placebo controlled trial of nebulised corticosteroids in acute respiratory syncytial viral bronchiolitis
}

A Cade, K G Brownlee, S P Conway, D Haigh, A Short, J Brown, D Dassu, S A Mason, A Phillips, R Eglin, M Graham, A Chetcuti, M Chatrath, N Hudson, A Thomas, P A J Chetcuti

Department of

Paediatrics and Child

Health, Clarendon

Wing, Leeds General

Infirmary, Belmont

Grove, Leeds LS2 9NS,

UK

A Cade

A Chetcuti

P A J Chetcuti

St James's University Hospital, Leeds LS9

7TF, UK

K G Brownlee

M Graham

M Chatrath

Seacroft Hospital, Leeds LS14 6UH, UK S P Conway

R Eglin

St Luke's Hospital, Bradford BD5 0NA,

UK

D Haigh

N Hudson

Huddersfield Royal Infirmary,

Huddersfield $\mathrm{HO} 3$

3AE, UK

A Short

A Thomas

Northern and

Yorkshire Clinical

Trials and Research

Unit, Leeds LS16 6QB,

UK

J Brown

D Dassu

S A Mason

A Phillips

Correspondence to:

Dr Cade

Accepted 14 October 1999

\begin{abstract}
Objective-To evaluate short and long term effects of giving nebulised budesonide early in respiratory syncytial viral (RSV) bronchiolitis.
\end{abstract}

Design-A multicentre randomised double blind placebo controlled trial.

Subjects-Infants admitted to hospital with their first episode of RSV positive bronchiolitis.

Intervention-Randomisation to receive either $1 \mathrm{mg}$ of nebulised budesonide (Bud) or placebo (Pla) twice daily from admission until 2 weeks after discharge. Follow up was for 12 months.

Main outcome measures-Duration of hospital admission, time taken to become symptom free, re-admission rates, general practitioner consultation rates, and use of antiwheeze medication during follow up.

Results-161 infants were studied. Both arms were similar with respect to initial clinical severity, age, sex, socioeconomic class, and tobacco exposure. Median time from first nebulisation to discharge: Bud and Pla, 2 days. Median number of days for $50 \%$ of infants to be symptom free for 48 hours: Bud, 10 days; Pla, 12 days. Respiratory re-admission rates in the 12 month follow up: Bud, 16\%; Pla, $18 \%$; median difference $(95 \%$ confidence interval $(\mathrm{CI})),-2(-14$ to 10$)$. Median respiratory related general practitioner attendances: Bud, 4.0; Pla, 4.5; median difference $(95 \% \mathrm{CI}),-1$ ( -2 to 0$)$. Percentage of infants receiving at least one prescription for antiwheeze medication during follow up, corticosteroids: Bud, $50 \%$; Pla, $60 \%$; difference $(95 \% \mathrm{CI}),-10$ ( -26 to 6); bronchodilators: Bud, $60 \%$; Pla, $67 \%$; difference $(95 \% \mathrm{CI}),-7$ ( -22 to 8$)$.

Conclusions-There are no short or long term clinical benefits from the administration of nebulised corticosteroids in the acute phase of RSV bronchiolitis.

(Arch Dis Child 2000;82:126-130)

Keywords: acute viral bronchiolitis; respiratory syncytial virus; inhaled corticosteroids

Acute viral bronchiolitis places a major demand on primary health care and paediatric hospital services in the UK during the winter months. It is the most common lower respira- tory tract illness of infancy and results in hospital admission in 1-2\% of all children under the age of 1 year. ${ }^{1}$ These infants account for $25 \%$ of paediatric bed occupancy in this period. Longer term sequelae are common after bronchiolitis, with up to $70 \%$ of infants experiencing recurrent cough and wheeze. ${ }^{2-7}$

The mainstay of hospital management is to provide adequate oxygenation, hydration, and nutritional support. Bronchodilators and antibiotics are often used but there is little evidence to support their therapeutic effectiveness. Systemic and inhaled corticosteroids are frequently prescribed as anti-inflammatory agents against the peribronchiolar inflammatory infiltration seen in viral bronchiolitis. ${ }^{8}{ }^{9}$ Beneficial effects from corticosteroids in the acute phase of viral bronchiolitis have been reported, ${ }^{10-12}$ with a $75 \%$ reduction in hospital re-admission rate because of recurrent respiratory illness demonstrated in one study. ${ }^{10}$ However, most studies suggest that corticosteroids have no clinical benefit when given in the acute phase of bronchiolitis. ${ }^{13-20}$

The aim of our multicentre, randomised, double blind, placebo controlled study was to evaluate the short and long term effects of giving a short course of nebulised budesonide to hospitalised infants with respiratory syncytial virus (RSV) positive bronchiolitis.

\section{Method}

Infants admitted to hospital with acute RSV positive bronchiolitis confirmed by immunofluorescence on a nasopharyngeal aspirate in five West Yorkshire hospitals during the winter of 1995-1996 were considered for entry into our study. If all inclusion and exclusion criteria were met (table 1), infants were randomised to receive either treatment or placebo. Randomisation was stratified by sex and centre. The primary end point was the proportion of infants who experienced at least one episode of coughing or wheezing over the 12 months after admission. Inpatient secondary end points included the length of time in hospital until fit for discharge, the requirement for supplemental enteral and parenteral feeds or fluids, and the length of time supplemental oxygen was needed. The type and frequency of any other medications were also recorded. Post-discharge secondary end points were the proportion of infants re-admitted to hospital with respiratory related problems, the length of time until symptom free (no coughing or wheezing for 48 consecutive hours), the number of general 
Table 1 Inclusion and exclusion criteria for entry into study

\begin{tabular}{ll}
\hline Inclusion criteria & Exclusion criteria \\
\hline Age less than 12 months of age & $\begin{array}{l}\text { Previous hospital admissions with respiratory } \\
\text { tract illnesses } \\
\text { Chronic respiratory illness }\end{array}$ \\
Confirmed RSV infection & $\begin{array}{l}\text { Congenital heart disease } \\
\text { Prematurity } \\
\text { Informed parental consent }\end{array}$ \\
Randomisation within 12 hours of admission & $\begin{array}{l}\text { Pre-existing immunodeficiencies } \\
\text { Prolonged exposure to systemic steroids }\end{array}$ \\
& Prosis \\
\end{tabular}

RSV, respiratory syncytial virus.

practitioner consultations for respiratory morbidity, and the type and amount of additional medication taken for respiratory symptoms in the 12 month follow up period.

On randomisation, detailed histories were recorded to include duration of symptoms before presentation to hospital, medical history, current and previous medications taken, immunisation record, family history of atopic illnesses, sibling number, pets, parental occupation, parental smoking habits, and the condition of housing. Treatment consisted of either $1 \mathrm{mg}$ of nebulised budesonide (Astra Pharmaceuticals Limited, Kings Langley, Hertfordshire, UK) suspended in vehicle or nebulised vehicle (sodium chloride, polysorbate 80 , citric acid, sodium citrate, and disodium edetate) twice daily. This was given immediately after randomisation and within 12 hours of admission until 14 days after being assessed as fit for hospital discharge, up to a maximum of 21 days. An infant was considered fit for hospital discharge only when at least 12 hours had lapsed since administration of the first trial solution, when they were feeding well, and when they no longer required supplemental oxygen. The trial solution and sidestream nebulisers (Medic-aid Limited, Pagham, West Sussex, UK) were manufactured and packaged to ensure the double blind nature of our study. Budesonide and placebo solutions were nebulised over a fixed 10 minute period, using a tightly applied face mask driven by $6 \frac{1 / 2}{2}$ litres/minute oxygen and a Medic-aid Portaneb CR60 compressor at home.

During hospital admission, a nursing hospital assessment form detailing components of a clinical symptom score and the use of other medications given was recorded twice daily before administration of the nebulised trial solution. The clinical symptom score ranked clinical severity from 0 to 11 based on heart rate, respiratory rate, supplemental oxygen requirements, and the presence or absence of chest wall retractions. After discharge, parents were asked to keep daily diaries recording daytime and nocturnal symptoms, additional medication use, and hospital or general practitioner contact. Daily diaries were kept for four weeks, after which they were used only on days when the infant showed symptoms of respiratory problems or when medication was used for symptoms. A research nurse made home visits two weeks and four weeks after discharge and then monthly for 12 months. These nurses completed an assessment of the compliance with trial medication; use of nontrial medication; visits to general practitioners or hospital; and the presence of damp, smokers, and pets in the house. General practitioner notes were reviewed 12 months after discharge.

\section{SAMPLE SIZE ESTIMATE}

From previous studies, the proportion of infants coughing or wheezing at least once during the 12 months after discharge is approximately $50 \% .^{2-7}$ To detect a reduction to $30 \%$ in the budesonide arm, at the 5\% significance level with $80 \%$ power, approximately 100 infants were required in each arm.

\section{STATISTICAL ANALYSIS}

Categorical data were analysed using the $\chi^{2}$ test on contingency tables. Continuous variables were analysed using $t$ tests or, where the distribution was skewed, the Wilcoxon-MannWhitney U test. Survival analysis with the proportional hazards model ${ }^{21}$ was used to compare the time from first nebulisation to resolution of symptoms and time from first nebulisation to discharge between the two arms. The results of these survival analyses were summarised by hazard ratios, a value greater than 1 suggested faster resolution of symptoms or discharge in the budesonide arm. Ninety five per cent confidence intervals (CI) are presented together with point estimates, including the difference in median number of general practitioner visits for respiratory morbidity. ${ }^{22}$ The significance level for all statistical hypothesis tests was set at $5 \%$. The analysis sample comprised all eligible patients who started the trial treatment, classified according to the treatment arm they were randomised to. Infants found to be ineligible after randomisation were excluded from the analysis. Follow up was stopped if an infant was transferred to intensive care.

\section{ETHICS}

Local ethics committee approval from the five centres was given for our study. Fully informed written parental consent was obtained for infants to be recruited.

\section{Results}

One hundred and sixty five infants were randomised into the study, 83 to budesonide, and 82 to placebo. Three infants from the placebo arm and one from the budesonide arm were subsequently excluded from the analysis: one (placebo) was transferred to a nonparticipating centre before the trial treatment was started; three infants were ineligible because two (both placebo) were RSV negative and one (budesonide) was previously exposed to systemic corticosteroids. The 161 remaining infants formed the sample for analysis. One infant in the budesonide arm and two in the placebo arm were transferred to intensive care units. There were no differences between the groups at randomisation in demographic variables (table 2) and in symptom duration and severity as measured by the clinical symptom score. The proportion of households with furry pets was higher in the placebo arm $(36 \% v$ $21 \%)$. 
Table 2 Demographic data for infants at enrolment

\begin{tabular}{lll}
\hline & $\begin{array}{l}\text { Budesonide } \\
(n=82)\end{array}$ & $\begin{array}{l}\text { Placebo } \\
(n=79)\end{array}$ \\
\hline Sex (male : female) & $45: 37$ & $47: 32$ \\
Atopic history & 43 & 38 \\
Number breast fed & 22 & 25 \\
Smoker in the house & 55 & 53 \\
Pets in the house & 17 & 28 \\
Damp in the house & 17 & 18 \\
Mean (SD) age (days) & $130(85)$ & $120(84)$ \\
Median (IQR) duration of symptoms & & \\
$\quad$ (days) & $4(2-6)$ & $4(2-5)$ \\
\hline
\end{tabular}

IQR, interquartile range.

PRIMARY END POINT

Coughing and wheezing episodes were much more common than anticipated, with 78 of 79 available diaries in the budesonide arm and 75 of 76 diaries in the placebo arm showing at least one day with coughing or wheezing over the 12 month follow up period. Therefore, no difference was found in terms of our primary end point $\left(\chi_{(1)}{ }^{2}=0.001 ; p=0.98 ; 95 \%\right.$ CI for difference, $-3 \%$ to $3 \%)$.

INPATIENT END POINTS

The number of days from first nebulisation until fit for hospital discharge were very similar, with hazard ratio $1.10,95 \%$ CI from 0.80 to $1.51\left(\chi_{(1)}^{2}=0.43 ; p=0.51\right)$, and median (interquartile range (IQR)) 2 days (1-3) for the budesonide group and 2 days (1-4) for the placebo group. Thirty five per cent of infants required intravenous fluids and/or nasogastric feed treatment in the budesonide arm and $37 \%$ in the placebo arm $\left(\chi_{(1)}{ }^{2}=0.03 ; \mathrm{p}=0.86 ; 95 \%\right.$ CI for difference, $-17 \%$ to $13 \%)$. Clinical symptom scores were only marginally lower in the budesonide arm throughout most of the hospital stay. All but one infant in both arms received additional prescribed medication while on the ward. These included ipratropium bromide, $\beta_{2}$ agonists, antibiotics, and oral or intravenous steroids. There were no differences in prescribing practices between the two arms.

\section{POST-DISCHARGE END POINTS}

Parental diaries were available for 79 infants in the budesonide group and 76 in the placebo group. At the 14 day follow up visit, 42 parents in the budesonide arm and 48 in the placebo arm told the research nurse that their child had been nebulised at home twice daily for 14 days after discharge. Daily symptom diaries were complete and reliable for the first 28 days after discharge $(96 \%$ complete in the budesonide arm and $98 \%$ complete in the placebo arm; two and six diaries, respectively, were stopped

Table 3 Postdischarge end points

\begin{tabular}{lllll}
\hline & $\begin{array}{c}\text { Budesonide } \\
(n=82)\end{array}$ & $\begin{array}{c}\text { Placebo } \\
(n=79)\end{array}$ & p Value & $95 \%$ CI \\
\hline $\begin{array}{l}\text { Hazard ratio for time to become } \\
\text { asymptomatic for 48 hours (day 1-28) }\end{array}$ & \multicolumn{2}{c}{1.41} & 0.07 & 0.98 to 2.04 \\
$\begin{array}{l}\text { Mean (SD) number of } \\
\quad \text { coughing/wheezing episodes } \\
\quad \text { (discharge to day 28) }\end{array}$ & $17.0(7.6)$ & $17.1(8.5)$ & 0.91 & -2.72 to 2.41 \\
$\begin{array}{l}\text { Number infants re-admitted for } \\
\text { respiratory morbidity over 12 months }\end{array}$ & 13 & 14 & 0.78 & $-14 \%$ to $10 \%$ \\
\hline
\end{tabular}

Confidence intervals are for differences in proportions or means or for the hazard ratio Hazard ratio of 1 implies no difference between treatments, $>1$ favours budesonide. CI, confidence interval. before day 28). Therefore, analysis of the time taken to become asymptomatic and the number of days with coughing or wheezing episodes was restricted to the first 28 days after discharge. This end point was censored on day 28 for infants still symptomatic on day 28 . The time taken for half the infants to become asymptomatic for 48 hours was 10 days (95\% CI, 10 to 13 ) in the budesonide arm and 12 days in the placebo arm (95\% CI, 10 to 16$)$. This difference was not significant in survival analysis $(p=0.07)$. Both groups had a similar number of days with coughing or wheezing in the first 28 days after hospital discharge (table 3). Hospital re-admissions over the 12 month period for respiratory morbidity were also very similar (13 of 82 and 14 of 79, respectively; table 3).

TWELVE MONTH GENERAL PRACTITIONER NOTE REVIEW

General practitioner notes relating to the year after discharge were available for review for 78 infants in the budesonide group and 72 in the placebo group. The number of general practitioner visits for respiratory morbidity were very similar, with median (IQR) 4 visits (2-6) in the budesonide arm and 4.5 visits (2-9) in the placebo $\operatorname{arm}\left(\chi_{(1)}{ }^{2}=1.12 ; \mathrm{p}=0.29 ;\right.$ median difference (budesonide-placebo), $-1 ; 95 \%$ CI, -2 to 0 ). Fewer infants in the budesonide group were prescribed bronchodilators $(60 \% v$ $\left.67 \% ; \chi_{(1)}^{2}=0.66 ; p=0.42\right)$ and steroids by their general practitioners $(50 \% \quad v \quad 60 \%$; $\left.\chi_{(1)}^{2}=1.42 ; \mathrm{p}=0.23\right)$; neither difference was significant.

There were no significant treatment effects in relation to respiratory related re-admissions to hospital, nocturnal or daytime wheezing, or general practitioner respiratory visits in patient subgroups defined by initial severity score, duration of symptoms at presentation, whether or not the infant had an atopic history, or the infant was exposed to cigarette smoke or damp in the household.

\section{Discussion}

Recurrent cough and wheeze after bronchiolitis is reported in up to $70 \%$ of infants after the acute illness..$^{2-7}$ Underlying airway abnormalities $^{2324}$ and/or a genetic predisposition have been implicated. The cause and effect of RSV infection on this chronic respiratory morbidity is not clear, but alteration of the $\operatorname{IgE}$ immune response to environmental allergens after bronchiolitis has been demonstrated. ${ }^{25}$ The acute inflammatory abnormalities within the airways of infants with acute bronchiolitis are similar to those seen in children with acute exacerbations of asthma. ${ }^{8}$ Therefore, it is possible that the administration of corticosteroids in the acute phase of the illness might have an effect on the natural history. A number of studies giving corticosteroids as a nebulised solution, ${ }^{10}{ }^{11} 13-15$ intramuscularly, ${ }^{16-18}$ and orally, ${ }^{12}{ }^{19} 20$ have examined this issue. Others have looked at the effects of steroid administration on the post-bronchiolitic symptoms. ${ }^{26}{ }^{27}$ Unfortunately, because of differing design, inclusion and exclusion criteria, end points, 
timing and duration of treatments, and different definitions of viral bronchiolitis, it is difficult to draw conclusive evidence for or against the use of corticosteroids in the acute or follow up phase of the illness.

Several papers have reported beneficial effects of steroids given in the acute phase of viral bronchiolitis. ${ }^{10-12}$ A $75 \%$ reduction in hospital re-admissions, general practitioner consultations, and paediatrician consultations was reported in a 12 month follow up study of infants admitted to hospital with bronchiolitis, who received nebulised budesonide from admission until they were symptom free. ${ }^{10}$ However, the study was retrospective, unblinded, and used historical controls. A further study demonstrated the beneficial effects of nebulised budesonide as an anti-inflammatory agent in reducing wheezy episodes and hospital admissions after bronchiolitis in the second half of a 16 week treatment period. ${ }^{11}$ However, the diagnosis of bronchiolitis was based on the presence of wheeze in conjunction with an upper respiratory tract illness. When atopic history was taken into account, benefits were no longer significant. A study reporting on cases of severe bronchiolitis requiring mechanical ventilation was able to demonstrate a significant reduction in duration of hospital admission in those children less than 24 months of age given oral prednisolone $(1 \mathrm{mg} /$ $\mathrm{kg} /$ day) for seven days compared with placebo. ${ }^{12}$ However, the diagnostic criteria for labelling these children as having bronchiolitis were vague and there were only seven children in each treatment arm. From this same study, among those children not requiring mechanical ventilation, symptoms improved more rapidly in the treatment group, but time to hospital discharge was not significantly shortened. No long term follow up data were available. Although these studies do show some clinical benefits of corticosteroids when given in the acute phase of bronchiolitis, most studies report no significant advantage in duration of hospital admission or long term morbidity. ${ }^{13-20}$

Our study design had rigid inclusion and exclusion criteria, a long follow up period, and took account of all previously documented confounding and conflicting variables. All our infants had immunofluorescence detection of the respiratory syncytial virus from a nasopharyngeal aspirate. All had clinical symptoms of viral bronchiolitis with upper respiratory tract infection, fine crepitations on chest auscultation, and evidence of respiratory distress.

The 200 patient sample size was calculated to detect a reduction in symptom rate for the budesonide group from $50 \%$ to $30 \%$ compared with placebo to demonstrate a real clinical benefit. Only 161 eligible infants were enrolled during the study period. Continuing our study into the next winter was considered inappropriate because the natural history might have changed from the first year. With hindsight, 39 more infants would not have been of consequence, because only two infants did not cough or wheeze during follow up.
It could have been that no apparent difference was demonstrated in terms of re-admission rate to hospital and general practitioner/paediatrician consultation rates because one group received more additional medication in the follow up period than the other, thereby masking real differences. No previous studies have looked at prescribing practices in the follow up period to exclude this potential confounding influence. We found that $50 \%$ of infants in the budesonide arm received at least one prescription for corticosteroids, either inhaled or oral, in the 12 months compared with $60 \%$ in the placebo arm $(p=0.23)$. Similarly, at least one $\beta_{2}$ agonist prescription was written for $60 \%$ of infants receiving budesonide and $67 \%$ of those receiving placebo $(p=0.42)$. Therefore, the study end points were not unfairly influenced by differing prescribing practices in the 12 month follow up period.

Previous studies have analysed the data for a family history of atopy and shown a better response to corticosteroids in this subgroup of infants with bronchiolitis. ${ }^{11}$ Half of our study population had a family history of atopy, defined as either a parent or sibling with eczema, hayfever, or asthma, and there was an equal distribution in each arm. Because our study was not large enough to show significant treatment effects within these subgroups, our analysis was aimed only at identifying trends suggestive of treatment effects within subgroups (that is, non-significant but positive treatment effect estimates), which could then be investigated in further trials. However, no such trends were found in relation to respiratory related re-admissions to hospital, nocturnal or daytime wheezing, and general practitioner respiratory visits between atopic and non-atopic infants or for subgroups defined by the presence of cigarette smoke or damp conditions in the home.

To ensure that any real but transient effects of corticosteroids on symptoms were not missed, the data over the first month after hospital discharge as well as over the whole 12 month period were analysed. The mean number of days of cough and/or wheeze in the first 28 days after hospital discharge were very similar (17 v 17.1 days). Parental data recording after the first month was poor and considered unreliable for analysis.

Our study might have failed to show any beneficial effects from administering corticosteroids because of poor lung drug deposition. It has been shown that less than $20 \%$ of a dose of nebulised budesonide reaches the mouth in infants with asthma and small children with normal tidal breathing. ${ }^{28}$ The lung drug deposition in our study population might have been even smaller because of tachypnoea, gas trapping, and increased secretions resulting from the bronchiolitic illness.

Our study is the largest of its kind ever reported. Very strict inclusion criteria ensured that participants had acute viral bronchiolitis and not viral associated cough and wheeze of infancy. The follow up of our infants has been intensive and prolonged, and data analysis has 
taken into consideration confounding variables. We have demonstrated no clinically meaningful benefit of nebulised budesonide in the acute phase of RSV bronchiolitis, either to hasten hospital discharge or to reduce long term respiratory morbidity, and we cannot recommend its use for treatment of this common condition. Steroids might have a role in post-bronchiolitic cough and wheeze, ${ }^{26} 27$ but this issue warrants further research.

We acknowledge the Astra Foundation for a full financial support grant to undertake this study.

1 McKenzie S. Respiratory tract infections. In: Forfar and Arneil's textbook of paediatrics. 4th ed. Edinburgh: Churchill Livingstone, 1992:638-40.

2 Rooney JC, Williams HE. The relationship between proved viral bronchiolitis and subsequent wheezing. $f$ Pediatr 1971;79:744-7.

3 Sims DG, Downham MAPS, Gardner PS, Webb JKG, Weightman D. Study of 8-year-old children with a history of respiratory syncytial virus bronchiolitis in infancy. $B M \mathcal{F}$ 1978;i:11-14.

4 Stokes GM, Milner AD, Hodges IGC, Groggins RC. Lung function abnormalities after acute bronchiolitis. F Pediat 1981;98:871-4

5 Pullan CR, Hey EN. Wheezing, asthma, and pulmonary dysfunction 10 years after infection with respiratory syncytial virus in infancy. $B M \mathcal{F} 1982 ; 284: 1665-9$.

6 Murray M, Webb MSC, O'Callaghan C, Swarbrick AS Milner AD. Respiratory status and allergy after bronchiolitis. Arch Dis Child 1992;67:482-7.

7 Kuikka L, Reijonen T, Remes K, Korppi M. Bronchial asthma after early childhood wheezing: a follow-up until 4.5-6 years of age. Acta Paediatr 1994;83:744-8.

8 Everard ML, Swarbrick A, Wrightman M, et al. Analysis of cells obtained by bronchial lavage of infants with respiratory syncytial virus infection. Arch Dis Child 1994;71:428-32.

9 Nahata MC, Schad PA. Pattern of drug usage in bronchiolitis. F Clin Pharm Ther 1994;19:117-18.

10 Goodwin A. An uncontrolled assessment of nebulised budesonide in the treament of acute infantile bronchiolitis. British fournal of Clinical Research 1995;6:113-19.

11 Reijonen T, Korppi M, Kuikka L, Remes K. Antiinf Arch Pediatr Adolesc Med 1996;150:512-17.

12 van Woensel JBM, Wolfs TFW, van Aalderen WMC, Brand PLP, Kimpen JLL. Randomised double blind placebo con- trolled trial of prednisolone in children admitted to hospial with respiratory syncytial virus bronchiolitis. Thorax tal with respirat

13 Daugberg P, Brenoe E, Forchhammer H, et al. A comparison between nebulised terbutaline, nebulised cortcosteroid and systemic steroid for acute wheezing in children up to 18 months of age. Acta Paediatr 1993;82: 547-51.

14 Sammartino L, Rasiah S, Wale L, Lines D. Budesonide in acute bronchiolitis. F Paediatr Child Health 1995;31:61-2.

15 Richter H, Seddon P. Early nebulized budesonide in the treatment of bronchiolitis and the prevention of postbronchiolitic wheezing. F Pediatr 1998;132:849-53.

16 Dabbous IA, Tkachyk JS, Stamm SJ. A double blind study on the effects of corticosteroids in the treatment of bronchiolitis. Pediatrics 1966;37:477-84.

17 Leer JA, Bloomfield NJ, Green JL, et al. Corticosteroid treament in bronchiolitis. Am f Dis Child 1969;117:495-503.

18 Roosevelt G, Sheehan K, Grupp-Phelan J, Tanz RR, Listernick R. Dexamethasone in bronchiolitis: a randomised controlled trial. Lancet 1996;348:292-5.

19 Springer C, Bar-Yishay E, Uwayyed K, Avital A, Vilozni D, Godfrey S. Corticosteroids do not affect the clinical or physiological status of infants with bronchiolitis. Pediatr Pulmonol 1990;9:181-5.

20 Klassen TP, Sutcliffe T, Watters LK, Wells GA, Allen UD, Li MM. Dexamethasone in salbutamol-treated inpatients with acute bronchiolitis: a randomized, controlled trial. 7 Pediatr 1997;130:191-6.

21 Parmar MKB, Machin D. Survival analysis: a practical approach. London: J Wiley, 1995.

22 Gardner MJ, Altman DG. Statistics with confidence. London: BMJ Publishing Group, 1989.

23 Young S, O'Keeffe PT, Arnott J, Landau LI. Lung function, airway responsiveness, and respiratory symptoms before and after bronchiolitis. Arch Dis Child 1995;72:16-24.

24 Martinez FD, Morgan WJ, Wright AL, Holberg C, Taussig LM. Initial airway function is a risk factor for recurrent wheezing respiratory illnesses during the first three years of life. Am Rev Respir Dis 1991;143:312-16.

25 Sigurs N, Bjarnason R, Sigurbergsson F, Kjellman B, Bjorksten B. Asthma and immunoglobulin $\mathrm{E}$ antibodies after respiratory syncytial virus bronchiolitis: a prospective cohort study with matched controls. Pediatrics 1995;95: $500-5$.

26 Carlsen K-H, Leegaard J, Larsen S, Ørstavik I. Nebulised beclomethasone dipropionate in recurrent obstructive episodes after acute bronchiolitis. Arch Dis Child 1988; 63:1428-33.

27 Wong J, Moon S, O'Callaghan C, Simpson H. Inhaled steroids reduce respiratory symptoms following bronchiolitis in oids reduce respiratory symptoms following bronchiolitis in infancy: a double-blind, randomised, placebo-controll

28 Lødrup Carlsen KC, Nikander K, Carlsen K-H. How much nebulised budesonide reaches infants and toddlers? Arch Dis Child 1992;67:1077-9. 